\title{
TUBUH PEREMPUAN DALAM SENI PERTUNJUKAN STUDY KASUS TARI ANGGUK PUTRI SRIPANGLARAS
}

\author{
Risah Mursih \\ Fakultas Seni Pertunjukkan, Institut Seni Indonesia Yogyakarta \\ e-mail : mursihrisa4@gmail.com \\ Diterima: 13 Agustus 2018. Disetujui : 8 November 2018. Dipublikasikan : 1 Desember 2018 \\ (O2018 - DESKOVI Universitas Maarif Hasyim Latif. Ini adalah artikel dengan akses terbuka di \\ bawah lisensi CC BY 4.0 (https://creativecommons.org/licenses/by/4.0/)
}

\begin{abstract}
ABSTRAK
Tari Angguk Sripanglaras dari Kabupaten Kulonprogo merupakan transformasi Angguk putra yang awalnya berfungsi sebagai bagian dari ritual agama, kini berfungsi menjadi hiburan. Perubahan fungsi Angguk sebagai hiburan ditandai dengan perubahan pada pelaku pertunjukan dan bentuk pertunjukan. Dengan ditarikan oleh penari perempuan, Angguk Putri Sripanglaras menjadi sebuah pertunjukan yang populer dan diminati oleh penonton yang didominasi oleh kaum laki-laki. Pendekatan penelitian yang dipilih adalah pendekatan gender. Dari perubahan bentuk pertunjukan, daya tarik Angguk Sripanglaras sangat kuat pada tubuh penari, yaitu tubuh perempuan. Pencitraan secara kultural ditunjukkan melalui tubuh perempuan. Dari pendekatan di atas diperoleh kesimpulan bahwa Angguk berfokus pada tubuh perempuan yang berkaitan langsung dengan inderawi. Penampilan utuh hasil paduan wajah cantik dengan ekspresi penuh senyum, lirikan mata, dengan balutan busana celana pendek ketat (hot-pants) ditambah gerak-gerak kekirig, goyang ngebor, megol, maka lengkaplah sudah bahwa perempuanlah yang membuat ketertarikan para penonton dalam sajian Angguk putri Sripanglaras.
\end{abstract}

Kata kunci: angguk, gender, tubuh perempuan

\section{ABSTRACT}

Angguk Sripanglaras dance from Kulonprogo is an angguk putra transformation which initially functions as part of religious rituals, now serves as entertainment. Angguk function is changed as entertainment are marked by changes in the performer and the form of the show. By being danced by female dancers, Angguk Putri Sripanglaras became a popular and dominated by male audience. The research approach chosen was a gender approach. From changes in the form of performances, the attraction of Angguk Sripanglaras is very strong on the dancer's body, namely the female body. Cultural imaging is shown through the female body. From the above approach, it can be concluded that Angguk focuses on the female body which is directly related to the senses. The full appearance of the combination of a beautiful face with an expression full of smiles, eye glances, wrapped in tight shorts (hot-pants) plus kekirig movements, ngebor dance, megol, then it's complete that women are the ones who attract the audience in Angguk Putri Sripanglaras.

Keywords: Angguk, Gender, Female body

\section{PENDAHULUAN}

Angguk umumnya dipahami sebagai salah satu kesenian rakyat yang berkembang di daerah pedesaan Kabupaten Kulonprogo, Daerah Istimewa Yogyakarta. Tari Angguk menggambarkan para muda-mudi yang bersukaria menyambut panen tiba. Disebut Angguk karena setiap mengawali dan mengakhiri tarian selalu melakukan gerak penghormatan dengan menganggukkan kepala. Penyajian tari Angguk selalu disertai dengan pantun-pantun rakyat yang berisi berbagai aspek kehidupan manusia, seperti: etika pergaulan hidup bermasyarakat, budi pekerti, nasihatnasihat, dan pendidikan kemasyarakatan lainnya.

Pada awal perkembangannya Angguk ditarikan oleh penari putra dengan gerak dan alat musik sederhana. Berfungsi sebagai syiar agama Islam berupa shalawatan yang berisikan syair puji-pujian kepada Nabi Muhammad SAW. Dalam pelaksanaannya pertunjukan ini menggunakan sesaji. 
Hal ini menandakan bahwa masyarakat masih percaya akan kekuatan lain yang ada di luar diri mereka. Dengan adanya sesaji diharapkan acara pementasan Angguk dapat berjalan lancar. Mereka percaya bahwa sesaji tersebut merupakan sarana memanjatkan doa kepada dhanyang atau penguasa alam ghaib desa setempat. Kesenian Angguk lebih dikenal dengan ciri ndadi atau trance.

Seiring dengan perkembangan zaman, maka kebudayaan pun mengalami perubahan. Pada perkembangannya Angguk mulai kurang diminati masyarakatnya. Oleh karena itu, Sri Wuryanti selaku pimpinan Angguk merasa prihatin dan tergugah untuk melestarikan kesenian rakyat Angguk agar tetap berkembang dan diminati masyarakat luas. Sri Wuryanti akhirnya mempunyai ide untuk membentuk Angguk yang dimainkan oleh penari perempuan, dan berfungsi sebagai hiburan. Perubahan fungsi tersebut mengandung konsekuensi untuk menyesuaikan diri dengan tuntutan perkembangan zaman.

Tubuh perempuan dikenal memiliki keindahan, tubuh perempuan sering dijadikan obyek untuk ketertarikan di dalam seni pertunjukan bahkan di dalam iklan-iklan, karena tubuh perempuan yang memiliki daya ketertarikan maka tubuh perempuan yang menjadi bahan untuk menarik penonton dalam seni pertunjukan. Manusia adalah makhluk dengan seksualitas; perempuan adalah individu yang lengkap, setara dengan laki-laki, hanya jika ia juga manusia dengan seksualitas. (Aquarini Priyatno Prabasmoro, 2006: 76). Sosok perempuan sebagai penebar pesona keindahan merupakan konstruksi sosial yang diciptakan oleh kaum laki-laki yang kemudian disepakati dan dilegitimasi bersama oleh masyarakat umum, dan ini merupakan realitas atau kenyataan (Herdiana, 2009, p. 176). Banyak sekali ketidak adilan terhadap jenis kelamin tertentu, umumnya perempuan, yang bersumber dari penandaan (stereotype) yang dilekatkan kepada mereka (Fakih, 2006, p. 16). Perempuan menjadi tumpuan dan norma yang diharapkan oleh masyarakat melalui mitos yang dituturkan dan visualisasinya diperkuat ke dalam seni pertunjukan.

Sri Wuryani selaku pimpinan bersikap luwes dalam melayani permintaan mereka yang mempunyai hajat atau yang mengundang pentas. Ketika dalam pertunjukan ada yang menginginkan Tari Angguk dikemas seperti dahulu sebagai syiar agama, misalnya dalam acara keagamaan seperti Ramadhan, maka pertunjukannya menyesuaikan dengan acara tersebut. Kostum yang dipakai lebih sopan, seperti celana di bawah lutut atau bahkan memakai rok panjang dan kerudung. Sri Wuryani berpendapat bahwa Angguk Sripanglaras memang menggunakan kostum celana pendek, namun itu bukan dimaksudkan menggoda para penonton karena sejak awal Angguk ditarikan oleh perempuan kostum yang dipakai adalah baju lengan panjang dan celana pendek yang akhirnya dianggap juga merupakan ciri khas dari kostum Angguk.
Dari perubahan bentuk pertunjukan, daya tarik Angguk Sripanglaras sangat kuat pada unsur sensualitas penari. Unsur sensualitas berkaitan dengan perempuan, pencitraan secara kultural ditunjukkan melalui tubuh perempuan. Angguk Sripanglaras sebagai sebuah pertunjukan mampu menyajikan tontonan yang "memanjakan" mata penonton terutama laki-laki namun juga sekaligus dipercaya oleh sebagian masyarakat berperan sebagai sarana ritual. Pencitraan perempuan di panggung pertunjukan mampu menyajikan pertunjukan yang mampu memikat penonton melalui unsur-unsur tari baik itu gerak, ekspresi, musik, dan kostum.

Untuk itu maka penelitian ini lebih ditekankan pada tubuh perempuan yang terdapat pada tari Angguk Sripanglaras, dengan menggunakan pendekatan penelitian gender. Pendekatan ini sebagai alat untuk mendeskripsikan, membedah dan menganalisis persoalan yang ada di dalam objek penelitian ini. Teori yang digunakan yaitu teori Gender.

\section{PEMBAHASAN}

Angguk putri Sripanglaras adalah kesenian yang lahir di Desa Pripih, Hargomulyo, Kokap, Kulonprogo. Kesenian Angguk merupakan satu dari sekian banyak jenis kesenian rakyat yang ada di Daerah Istimewa Yogyakarta. Tari Angguk merupakan kesenian rakyat yang berkembang di daerah pedesaan Kabupaten Kulonprogo, Daerah Istimewa Yogyakarta. Tari Angguk menggambarkan para muda-mudi bersukaria menyambut panen tiba dan disebut Angguk karena setiap tarian selalu diawali dan diakhiri penghormatan dengan menganggukkan kepala. Kesenian Angguk disajikan dengan tema hiburan karena Tari Angguk menggambarkan muda mudi yang bersuka ria menyambut panen tiba. Kesenian Angguk disajikan dalam bentuk tari kelompok terdiri dari 10-12 penari. Umumnya alat musik yang digunakan untuk mengiringi tari Angguk yaitu bedug, kendang, saron, keyboard, rebana, vokal. Kostum yang digunakan menyerupai kompeni Belanda dengan baju lengan panjang yang berpangkat, celana pendek (hot-pants), kaos kaki, topi, dan kacamata. Tari Angguk biasanya dipentaskan mulai pukul 20.00 WIB- 01.00 WIB dengan urutan penyajian pembukaan, tari berpasangan, ndadi/trance, dan penutup. Dalam prakteknya seringkali Tari Angguk juga disajikan dalam durasi yang lebih singkat dan tidak selalu di malam hari.

Ditinjau dari segi fungsi kesenian Angguk pada masa sekarang ini masih mengalami perubahan dan penambahan fungsi, yaitu yang pada awalnya sebagai syiar agama Islam berupa Sholawatan, pada masa sekarang ini kesenian Angguk berfungsi sebagai sarana hiburan, dalam arti lain sebagai media syiar agama tetap, dalam perkembangan sebenarnya bertambah dalam fungsi sebagai hiburan. Perubahan 
tersebut sebagai konsekuensi untuk menyesuaikan diri dengan tuntutan perkembangan zaman.

Pada budaya Jawa perempuan dan kecantikan diibaratkan sebagai sekeping mata uang logam dengan dua sisi yang saling berdekatan yang mengacu pada hal yang bersifat feminitas dan keibuan serta perempuan dianggap sebagai simbol keindahan yang mengandung makna kehalusan, keanggunan, kelembutan. Perempuan ketika dibicarakan seakan menjadi tidak terlepas dari penampilan fisiknya, segala bentuk interpretasi dari tubuh perempuan mulai dari ujung rambut hingga ujung kaki telah menghasilkan banyak permasalahan pada setiap perbincangan. Berbicara mengenai perempuan selalu dikaitkan dengan tubuh sensualitas karena paras wajah dan keindahan tubuh yang dimilikinya dijadikan sebagai daya tarik mereka. Kriteria yang melekat di dalam perempuan dimana pria dapat terpengaruh olehnya karena di dalam tubuh perempuanlah sensualitas itu melekat dan menjadikannya daya tarik tersendiri. Diantaranya meliputi postur tubuh, lirikan mata, rambut yang panjang dan menawan, bibir, dada, pinggul, betis juga termasuk daya tarik sensual yang melekat di dalam tubuh perempuan. Selain itu di dalam tubuh penggunaan pakaian juga termasuk di dalamnya, penggunaan pakaian yang ketat dan sepatu hak tinggi (high heels) akan menambah unsur sensualitas tersebut.

Penelitian ini memfokuskan pengkajian tubuh perempuan dalam Tari Angguk putri. Di dalam Tari Angguk putri kostum sangat berperan untuk menonjolkan kecantikan penari. Kostum di sini berperan penting menghiasi tubuh para penari untuk mempengaruhi kecantikan penari Angguk sehingga berfungsi untuk mencuri perhatian penonton. Berbeda dengan Tari Angguk putra walaupun memakai kostum yang sedikit terbuka namun ketrrtarikan itu tetap berada di penari perempuan, karena seorang perempuan memiliki daya pikat yang membuat ketertarikan para penonton. Oleh sebab itu mengapa penari perempuan sagat berperan penting di dalam Tari Angguk karena sangat jelas untuk kebutuhan pemasaran pun sangat menarik tubuh perempuan di dalam Tari Angguk ini. Penari Angguk sebagai titik perhatian dalam pertunjukan Angguk tentunya tidak lepas dari tubuh penari khususnya perempuan. Berpenampilan sebaik mungkin, serta kostum Angguk yang indah dan menarik dengan ciri khas baju ketat lengan panjang dan celana pendek (hot-pants), memunculkan ketertarikan tersendiri di dalam Tari Angguk.

Rias untuk Tari Agguk menggunakan rias korektif, busana yang dikenakan para penari Angguk adalah celana pendek (hot-pants), dan baju lengan panjang yang ketat dengan asesoris di pundak yang berumbai-rumbai sehingga akan bergerak jika digetarkan. Dengan busana seperti itu ditambah dengan gerakan kaki ditempat serta pinggul yang bergoyang-goyang akan menunjukkan kesan sensual. Tidak bisa dipungkiri dan sudah sangat jelas, bahwa penonton khususnya kaum laki-laki tertarik dengan hal seperti itu, disaat melihat para penari Angguk putri memakai celana pendek serta baju ketat dan bergoyang-goyang. Walaupun sekarang para penari Angguk sudah menggunakan stocking warna kulit, namun tetap kelihatan lekukan-lekukan atau bentuk paha para wanita yang membuat betah para laki-laki untuk memandang dan bertahan dihadapan penari seperti itu. Ditambah baju yang ketat akan membuat para penonton khususnya kaum laki-laki seolah terhipnotis memandang ke penari. Dengan memakai baju ketat ketika para penari bergerak, lekuk-lekukan tubuh akan semakin menonjol terutama bagian dada. Tidak itu saja, di bagian celana yang dihiasi rumbai, juga dibagian baju yaitu pangkat yang dihiasi dengan bulu-bulu atau rumbai-rumbai dari manik-manik, akan menambah keindahan dibagian kostum tersebut ketika penari melakukan gerak kekirig (gerak bahu yang digetarkan), maka hiasan yang ada di pangkat bahu tersebut ikut bergerak. Hal ini menambah keindahan di dalam gerak akibat efek yang ditimbulkan dari hiasan kostum tersebut. Sudah jelas hal itu akan membuat perhatian para penonton dengan melihat paha dan betis para penari Angguk Sripanglaras yang mulus itu, jelaslah akan muncul sensualitas di dalamnya karena paha dan betis merupakan bagian sensualitas di dalam tubuh perempuan.

Instrumen yang paling penting di dalam tari Angguk adalah Bedug, kendang, dan vocal, terdapat kesensuaian di dalam musik Angguk ini ketika bedug, kendang serta vocal dimainkan karena musik di dalam tari Angguk ini sangat bisa dinikmati. Adapun contoh lagu dalam pertunjukan Angguk Sripanglaras adalah "Ikan cucut mandi di laut, ikan cucut mandi di laut, kena ombak bergoyang butut, andheng-andheng di atas mulut, siapa mandeng pasti kepincut". Kesensualan terdapat dibagian kendang dan bedhug ketika kendhang dan bedhug dipukul, bersamaan dengan itu gerak para penari adalah megol atau pinggul bergoyang ke kanan ke kiri mengikuti ritme hentakan bedhug dan kendhang. Dengan bertambahnya alat kendhang jaipongan dan keyboard serta lagu-lagu dangdut kesensualan itu akan muncul karena ditambah dengan pembawaan gerak penari Angguk. Dimana gerak penari akan memunculkan kesensualan seperti goyang ngebor, goyang jaipongan.

\section{KESIMPULAN}

Angguk adalah suatu bentuk seni pertunjukan kelompok yang selalu ditarikan berpasangan. Pada hakikatnya tarian ini merupakan tari kerakyatan yang berasal dari Kabupaten Kulon Progo dan berfungsi sebagai Sholawatan, namun dengan adanya perkembangan zaman, Tari Angguk ini bergeser fungsi menjadi hiburan dengan alasan agar lebih 
menarik dan banyak diminati para penonton karena dulunya ditarikan oleh kaum laki-laki dan sekarang ditarikan oleh perempuan.

Pertunjukan tentunya banyak digemari dan diminati penonton ketika penarinya perempuan, karena perempuan mempunyai keindahan dan paras wajah yang cantik. Sudah sangat jelas kalau penonton khususnya para lelaki tertarik dengan adanya penari perempuan yang memiliki tubuh menarik.

Pada sisi yang lain penari Angguk berusaha menjaga dirinya berpenampilan menarik dihadapan para penonton. Penari yang masih muda, dengan penampilan yang ramah dan penuh senyum serta dandan cantik agar menarik para penonton. Untuk kostum para penari Angguk, sudah tidak asing lagi bahwa kostum yang dipakai adalah baju ketat lengan panjang dan celana pendek (hot-pants). Lekukanlekukan tubuh, serta paha dan betis para penari sudah jelas kelihatan. Dengan kostum yang seperti itu munculah Sensualitas para penari Angguk tersebut. Perwujudan sensualitas juga dapat dilihat dari berbagai unsur yang lain seperti rias, ekspresi, musik serta gerak.

Seorang penari selalu ingin tampil cantik dan terlihat indah untuk dipandang maka dari itu seorang penari tidak lupa untuk selalu menggunakan rias. Penari sangatlah kreatif untuk merias diri dari memakai alas bedak, eyes shadow, eyes liner, maskara, blush on, bulu mata, dan lipstik/pemerah bibir agar terlihat sensual. Disamping rias, ekspresipun juga selalu ada di dalam pertunjukan. Dipertunjukan Angguk inilah ekspresi genit ada di dalamnya, dengan lirikan, senyuman, serta ekspresi genit yang membuat perhatian para penonton khususnya kaum pria.

Gerak kekirig, gerak megol, serta anggukan kepala selalu ada di dalam Tari Angguk, di dalam gerak kekirig itu menggunakan gerak bahu yang digetarkan, ketika gerak bahu itu digetarkan maka dada itu pun akan ikut gerak dan disitulah pasti akan menjadi pusat perhatian banyak orang, hampir sama ketika anggukan kepala, ketika penari menganggukan kepala pastilah pandangan penonton langsung memandang ke wajah dan leher. Dimana leher juga menjadi pusat dari tubuh perempuan. Pusat yang membuat ketertarikan di dalam tubuh perempuan yang ada di dalam gerak megol yaitu pantat dan betis, sudah jelas bahwa megol adalah pinggul yang digerakan ke kanan dan ke kiri dengan kedua kaki jalan ditempat. Pastilah yang akan menjadi fokus dalam gerakan itu adalah pantat dan betis dimana pantat dan betis adalah bagian Sensualitas daritubuh perempuan.

Tubuh perempuan dalam seni pertunjukan Angguk merupakan wujud utama bagi eksistensi kesenian Angguk di Kabupaten Kulonprogo. Keberadaannyalah yang mempertahankan kehidupannya di dalam masyarakat karena tubuh perempuan dalam seni pertunjukan mampu membuat ketertarika di dalam pertunjukan dibandingkan tubuh laki-laki, Perwujudan tubuh perempuan juga menimbulkan permasalahan tersendiri yang muncul di luar pertunjukan Tari Angguk, kenyataannya bahwa banyak anggapan-anggapan negatif yang menempel pada penari Angguk tersebut. Penari Angguk dianggap sebagai perempuan penggoda, banyak para istri yang merasa cemburu pada penari Angguk karena para suami mereka sering pulang larut malam bahkan sampai pagi ketika melihat pertunjukan Angguk dan perasaan ketakutan para istri jika suami terpikat oleh penari Angguk tersebut. Hal tersebut dapat menyebabkan turunnya martabat penari Angguk hingga akhirnya berpengaruh pula kepada penilaian dan tanggapan orang terhadap dunia tari Angguk itu sendiri.

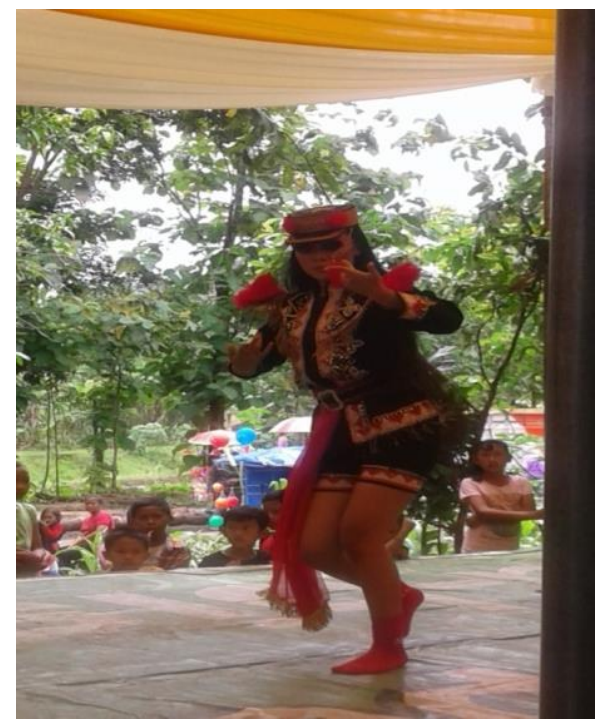

Gambar. 1. Pose penari saat mengalami trance. (dok. Ela, 2014).

\section{DAFTAR PUSTAKA}

Abdullah, I. (2007). Konstruksi dan reproduksi kebudayaan. Yogyakarta: Pustaka Pelajar.

Arvend, M. (2014). Sensualitas Wanita Penjaja Seks Dalam Metafora. Institut Seni Indonesia Yogyakarta.

D. Linchtenberg, J. (2008). Sensuality and Sexsuality Across The Divide Of Shame. New York: The Andytic Press Taylor\& Francis Group.

Fakih, M. (1996). Menggeser Konsepsi Gender dan Transformasi Sosial. Yogyakarta: Pustaka Pelajar.

Fakih, M. (2006). Analisis gender \& transformasi sosial. Yogyakarta: Pustaka Pelajar.

Hadi, Y. S. (2000). Peran Wanita Pedesaan Dalam Pelestarian Seni Pertunjukan Rakyat. Ekpresi, l(1).

Hadi, Y. S. (2003). Aspek-Aspek Dasar Koreografi Kelompok. Yogyakarta: Elkaphi.

Hadi, Y. S. (2005). Sosiologi tari: sebuah pengenalan awal. Yogyakarta: Pustaka.

Hadi, Y. S. (2011). Koreografi: bentuk, teknik, isi. 
Yogyakarta: Cipta Media

Hadi, Y. S. (2012). Seni pertunjukan dan masyarakat penonton. Yogyakarta: BP ISI Yogyakarta.

Herdiana, E. (2009). Peran Dan Citra Perempuan Dalam Tari Sunda, editor. Endang Catur Wati, Pesona Perempuan Dalam Sastra Dan Seni Pertunjukan. Bandung: Sunan Ambu STSI Press.

Irianto, A. M. (2005). Tayub, antara ritualitas dan sensualitas: erotika petani Jawa memuja dewi. Semarang: Laboratorium Seni dan Kebudayaan Lengkongcilik Universitas Diponegoro.

Islam, B. P. (2014). Erotisme Dalam Fotografi, Studi Kasus Foto Pentas Biduanita Dangdut Dalam Akun Facebook. Institut Seni Indonesia Yogyakarta.

Koentjaraningrat. (1984). Manusia dan Kebudayaan di Indonesia. Jakarta Pusat: Djambatan.

La Meri. (1986). Elemen-Elemen Dasar Komposisi Tari. Yogyakarta: Lagaligo.

Mardalis. (2004). Metode Penelitian. Jakarta: PT Bumi Angkasa.

Martono, H. (2008). Sekelumit Ruang Pentas: Modern dan Tradisi. Yogyakarta: Cipta Media.

Maryaeni. (2005). Metode Penelitian Kebudayaan. Jakarta: PT Bumi Putra.

Padila, A. (2013). Representasi Sensualitas Perempuan Dalam Iklan. Universitas Islam Sunan Kalijaga Yogyakarta.

R. M. Soedarsono. (n.d.). Seni Pertunjukan Indonesia dan Pariwisata. Yogyakarta: Arti Line.

Rader, M. (1990). A Modern Book Of Esthetics An Antology. Edition University Of Washington,
Terjemahan Abdul Khadir. Yogyakarta: Institute Seni Indonesia Yogyakarta.

Sanden Bantul. (2014). Tari Angguk Sripanglaras.

Sekolah Vokasi Universitas Gadjah Mada. (2014). TARI ANGGUK SRIPANGLARAS ACARA PUNCAK EVOFEST (ENGLISH VOCATIONAL FESTIVAL).

Smith, J. (1975). Komposisi Tari: Sebuah Petunjuk Praktis Bagi Guru, terjemahan Ben Suharto. Yogyakarta: Ikalasti Yogyakarta.

Sri, N. (2009). Ekspresi Perempuan Dalam Seni Pertunjukan, editor. Endang Caturwati, Pesona Perempuan Dalam Sastra Dan Seni Pertunjukan. Bandung: Sunan Ambu STSI Press.

Sudarsono. (1989). Seni pertunjukan Jawa tradisional dan pariwisata di Daerah Istimewa Yogyakarta. Yogyakarta: Departemen Pendidikan dan Kebudayaan, Direktorat Jenderal Kebudayaan, Proyek Penelitian dan Pengkajian Kebudayaan Nusantara, Bagian Proyek Penelitian dan Pengkajian Kebudayaan Jawa.

Sudarsono. (2002). Seni pertunjukan Indonesia di era globalisasi. Yogyakarta: Gadjah Mada University Press.

Sumaryono. (2011). Antropologi Tari. Yogyakarta: Badan Penerbit ISI Yogyakarta.

Sumaryono. (2012). Ragam seni pertunjukan tradisional di Daerah Istimewa Yogyakarta. Yogyakarta: UPTD Taman Budaya, Dinas Kebudayaan Provinsi Daerah Istimewa Yogyakarta. 
Risah Mursih / DESKOVI : Art and Design Journal , Vol. 1, No.1, Desember 2018, 17-22

(Halaman ini sengaja dikosongkan) 